\title{
Should health care dollars be used to house the homeless?
}

\author{
n Cite as: CMAJ 2018 October 29;190:E1291-2. doi: 10.1503/cmaj.109-5671
}

Posted on cmajnews.com on Oct. 10, 2018.

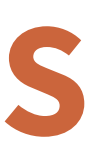
hifting funds from health care budgets to housing programs can save money and improve health outcomes, according to Dr. Mitchell Katz, president and chief executive officer of NYC Health + Hospitals. But Toronto-based experts caution that improving health outcomes among homeless people is not that simple.

At a recent lecture in Toronto, Katz described the housing strategies he helped initiate while working in hospitals in San Francisco and Los Angeles. The idea hit him in the early nineties, when he saw the same homeless patients coming in and out of hospitals. They'd get a barrage of tests and then be discharged back into the street.

"It struck me in two ways, on a humanitarian level ... but equally, wow, the amount of money we spent in the last three to four days could have housed this person and three of his friends for a year," said Katz.

In San Francisco, Katz founded Housing for Health, which used public health and other funding to house 1300 medically complex homeless people over 13 years. In
2010, he became the director of the Los Angeles County Department of Health Services. There, Katz used $\$ 250,000$ from a $\$ 3.5$ billion health services budget to house homeless people. He secured millions more from private donations and city funds. The Los Angeles Housing for Health initiative saw 7000 homeless people get apartments within a five-year period.

An independent analysis of the Los Angeles project showed that use of inpatient medical services were reduced by $76 \%$ in the year after a person was housed. The total cost of health services provided

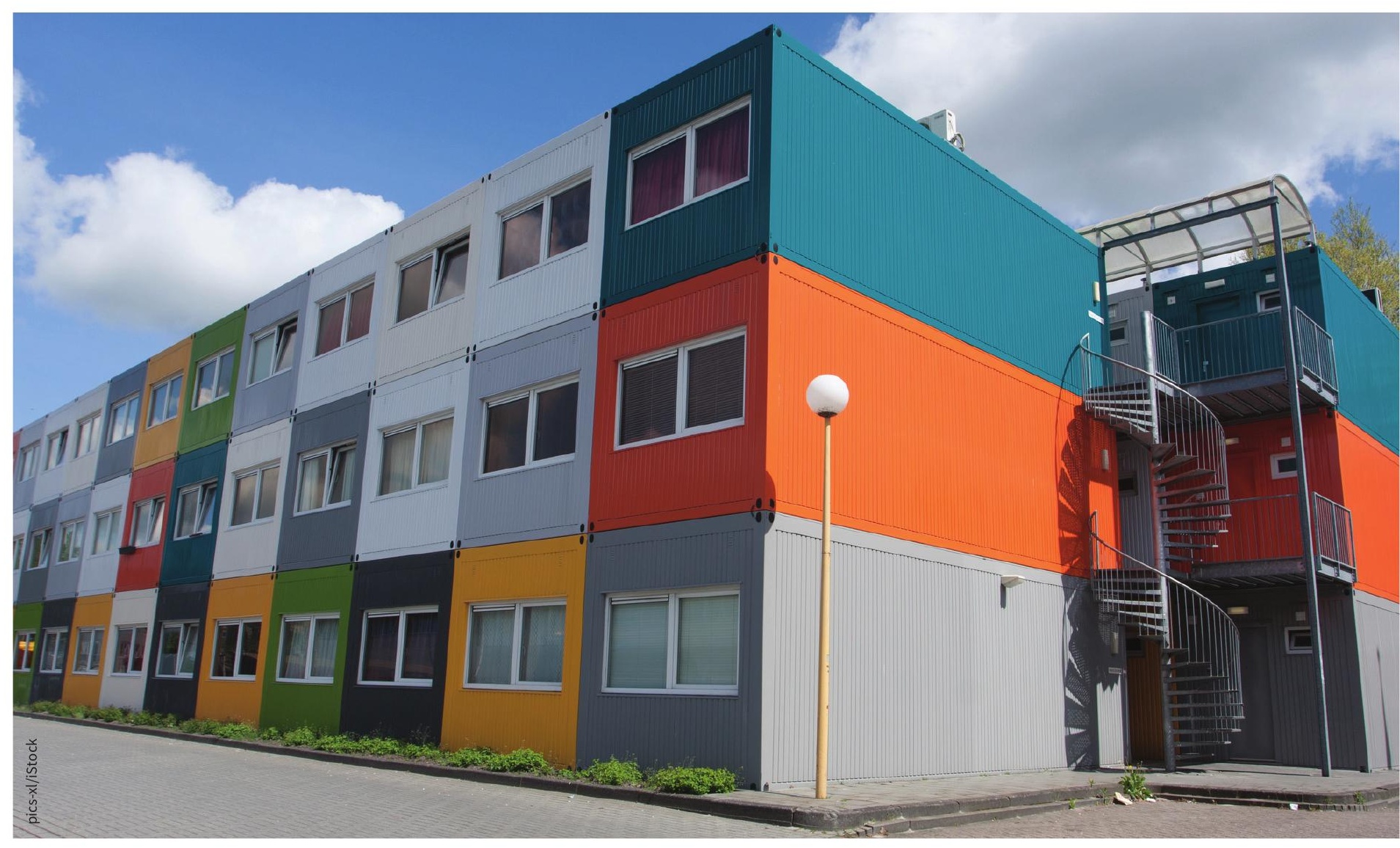

Some advocates for affordable housing for the homeless propose creating apartments from shipping containers. 
to high-needs people fell by $20 \%$ in the year after housing was provided.

"If all the people in Toronto decide that the 5000 to 10000 homeless people in Toronto will be housed in three years, that could be done," said Katz.

But according to Dr. Stephen Hwang, director of the Centre for Urban Health Solutions at St. Michael's Hospital, while ending homelessness should be a goal in and of itself, it wouldn't save money. Housing someone who is homeless costs around $\$ 15,000$ a year in Toronto, he said, and "health system utilization exceeds $\$ 15,000$ a year only for a select group of very high utilizers."

The only example of substantial health care dollars being used for housing in Canada that Hwang could point to is the Ontario Ministry of Health and Long-Term Care's mental health supportive housing program. The ministry spends $\$ 100$ million to house Ontarians struggling with mental health issues who are homeless or at risk of being homeless. A 2016 auditor general report found that the ministry hasn't evaluated if the program saves money, and high-needs patients are often bumped down the waiting list because the supportive housing they need isn't available.

One novel approach to providing housing could be to use shipping containers, which are plentiful in North America because it's too expensive for some foreign exporters to bring them back, noted Katz. In Los Angeles, shipping containers were the building blocks for a modern, five-storey apartment complex designed to house people struggling with homelessness.

Shipping containers can be stacked and used to create high-density housing, so the solution would work in a city like Toronto, said Mary-Anne Bedard, director of service planning and integrity for the Shelter, Support and Housing Administration at the City of Toronto. And they'd fare well in cold weather. "They're fully insulated," she said.

Despite the hype, however, shipping containers tend to make for incredibly small living quarters, and raise "difficult questions for progressives," Katz said. "Our goal is to build wonderful housing for homeless people that's integrated into neighbourhoods, so the formerly homeless are not segregated into a Lego ghetto; on the other hand, you have to be practical."

A more systematic solution for Toronto could be redirecting some revenue from a tax already paid by condo developers (to support community improvements like planters, public art and specialized lighting) to create subsidized, affordable housing. It can take a decade to see an affordable housing project to fruition due to NIMBYism and lack of political will, noted Katz, but the time drops dramatically when developers include affordable housing in luxury condo projects.

The housing for health philosophy is gaining momentum in North America, and not just among advocates of vulnerable populations. As Katz pointed out, US private insurers are beginning to provide grocery benefits and housing supports because they're "actually more effective at promoting health than a lot of MRI scans or unnecessary medications that we use quite liberally."

Wendy Glauser, Toronto 